\title{
Stability of microcrystalline silicon for thin film solar cell applications
}

\author{
F. Finger, R. Carius, T. Dylla, S. Klein, S. Okur and M. Günes
}

\begin{abstract}
The development of microcrystalline silicon $(\mu \mathrm{c}-\mathrm{Si}: \mathrm{H})$ for solar cells has made good progress with efficiencies better than those of amorphous silicon $(\mathrm{a}-\mathrm{Si}: \mathrm{H})$ devices. Of particular interest is the absence of light-induced degradation in highly crystalline $\mu \mathrm{c}-\mathrm{Si}: \mathrm{H}$. However, the highest efficiencies are obtained with material which may still include a-Si:H regions and lightinduced changes may be expected in such material. On the other hand, material of high crystallinity is susceptible to in-diffusion of atmospheric gases which, through adsorption or oxidation, affect the electronic transport. Investigations are presented of such effects concerning the stability of $\mu$ c$\mathrm{Si}: \mathrm{H}$ films and solar cells prepared by plasma-enhanced chemical vapour deposition and hot wire chemical vapour deposition.
\end{abstract}

\section{Introduction}

The recent popularity of microcrystalline silicon ( $\mu \mathrm{c}-\mathrm{Si}: \mathrm{H})$ began with the first successful applications of this material as an absorber layer in thin film solar cells [1-3] and, most importantly, when it was reported [3] that such solar cells did not suffer from the notorious light-induced degradation, known as the Staebler-Wronski effect (SWE), which is observed in amorphous silicon [4]. Easy fabrication of $\mu \mathrm{c}-\mathrm{Si}: \mathrm{H}$, i.e. with only a few modifications to the established plasma-enhanced chemical vapour (PECVD) process used for a-Si:H, made it possible for many research groups to begin research and development work on $\mu \mathrm{c}-\mathrm{Si}: \mathrm{H}$. Considerable progress has been made since then concerning the fabrication of $\mu \mathrm{c}-\mathrm{Si}: \mathrm{H}$ material and solar cells and the improvement of device quality. $\mu \mathrm{c}-\mathrm{Si}: \mathrm{H}$ is a mixture of various amounts of different structural components; crystalline grains, amorphous or disordered regions including grain boundaries and voids. In addition, structural inhomogeneity along the growth axis and a very critical substrate dependence of the nucleation process is observed. These material properties and the resulting devices were investigated in great detail and it soon became clear that under certain conditions in the material preparation process, or with respect to the material itself, instability or metastability phenomena may also occur in $\mu \mathrm{c}-\mathrm{Si}: \mathrm{H}$ and may affect solar cell efficiency.

It was shown that the solar cells containing $\mu \mathrm{c}-\mathrm{Si}: \mathrm{H}$ as the absorber layer display the highest efficiency if the material is prepared near the threshold between microcrystalline and all-amorphous structure growth $[5,6]$. Such solar cells show much higher open circuit voltages $\left(V_{\mathrm{OC}}\right)$ compared to solar cells with material grown under highly crystalline growth conditions [5-8]. Whether amorphous structure in such

(C) IEE, 2003

IEE Proceedings online no. 20030636

doi:10.1049/ip-cds:20030636

Paper first received 10th February and in revised form 20th May 2003

F. Finger, R. Carius, T. Dylla and S. Klein are with the Institute of Photovoltaics, Forschungszentrum Jülich, 52425 Jülich, Germany

S. Okur and M. Günes are with the Department of Physics, Izmir Institute of Technology, Urla, 35437 Izmir, Turkey material is the reason for the high $V_{\mathrm{OC}}$ values, e.g. leading to an increase in the 'effective' mobility gap, has not yet been clearly resolved [9]. Structural investigations on optimised solar cells showed very little to no amorphous components in material grown by PECVD [8, 10, 11]. For the case of hot wire (HW) CVD material with still higher $V_{\text {OC, }}$, however, a considerable $(50 \%)$, but homogeneously distributed, amorphous volume fraction was found [7]. The investigations are complicated by the substrate dependence of growth, which results in different structures for material grown on glass or $\mathrm{Si}$ wafers and material grown in solar cells on highly crystalline contact layers. In any case, the presence of an amorphous phase could result in lightinduced metastability, which has now been confirmed [12].

A second point of concern is related to the porosity in $\mu \mathrm{c}-\mathrm{Si}: \mathrm{H}$, in particular in material with a high crystalline volume fraction. A very careful and detailed investigation on $\mu \mathrm{c}-\mathrm{Si}: \mathrm{H}$ by Vepřek et al. [13] reports, for material prepared by the chemical transport deposition process, that atmospheric gas adsorption and/or oxidation affect surface states, electronic transport and electron spin density. It will be important to investigate and identify these effects in state-of-the-art material prepared by PECVD and HWCVD. This is particularly the case since it is generally observed that deposition conditions which lead to the technologically desirable higher deposition rates tend to enhance a porous structure. Also attempts to grow material with large grain size, usually at higher deposition temperatures in order to improve carrier mobility, frequently result in porous material with poor grain boundary passivation. The two deposition techniques, PECVD and HWCVD, used for the growth of the $\mu \mathrm{c}-\mathrm{Si}: \mathrm{H}$ samples are here considered to be equivalent concerning the resulting structure and the electronic properties of the material. It was shown that material with very similar properties can be grown with both techniques if the deposition conditions are adjusted appropriately $[14,15]$. The temperature and the silane/hydrogen mixture are found to be the most critical deposition parameters to determine the structure and the electronic properties. A note seems necessary. If we say 'similar', this refers to material with a given crystallineamorphous structure composition. As different applications of $\mu \mathrm{c}-\mathrm{Si}: \mathrm{H}$ might require material with different volume 
fractions for optimum performance, knowledge of the crystalline volume fraction is a key issue for material studies, device development and comparison of material from different deposition techniques.

However, there are also indications for differences in the material structure and performance of solar cells including $\mu \mathrm{c}-\mathrm{Si}: \mathrm{H}$ grown with PECVD or HWCVD [5-8, 10-12]. Details will have to be investigated in future studies.

The instabilities and metastabilities of the porous structure of the highly crystalline material on the one hand, and amorphous inclusions in 'threshold' material with optimum solar cell performance on the other, need to be explored for the material and also for solar cells. There have only been a few investigations on recently prepared material [16-20]. In the present paper we will discuss the results of some of the phenomena for material and solar cells prepared by PECVD or HWCVD and compare these results with earlier investigations.

\section{Experimental}

The material was prepared in the chamber for intrinsic $\mu \mathrm{c}-$ $\mathrm{Si}: \mathrm{H}$ deposition of multichamber deposition systems [5-12, 14, 15]. Special consideration was given to the purity standards of the vacuum system and the gas supply system to prevent impurity contaminations (such as oxygen) of the $\mu \mathrm{c}-\mathrm{Si}: \mathrm{H}$ layers during growth.

The PECVD material was prepared at $95 \mathrm{MHz}$. For the HWCVD system we use a tantalum wire arrangement. The substrate size in both cases was $10 \times 10 \mathrm{~cm}^{2}$ with homogeneous deposition across the area. Silanehydrogen mixtures were used as process gases. The silane concentration $S C=\left[\mathrm{SiH}_{4}\right] /\left(\left[\mathrm{SiH}_{4}\right]+\left[\mathrm{H}_{2}\right]\right)$ was varied to obtain material ranging from highly crystalline to amorphous. As a semi-quantitative measure of the crystalline volume fraction we use the Raman intensity ratio $I_{c}^{R S}=$ $\left(I_{500}+I_{520} / I_{480}+I_{500}+I_{520}\right)$. The values $I_{480}+I_{500}+I_{520}$ are the integrated intensities of the contributions at the respective wave numbers to the Raman spectrum, which are related to disordered/ amorphous and crystalline regions, respectively [21].

The material was deposited onto borosilicate glass and $\mathrm{Si}$ wafers for electrical, Raman and infrared measurements. For ESR measurements, material was deposited onto $\mathrm{Al}$ foil and glass substrates. The films were removed from the $\mathrm{Al}$ by $\mathrm{HCl}$ etching. The powder was rinsed in deionised water, dried at ambient temperature and sealed in a $\mathrm{He}$ atmosphere in quartz tubes. Alternatively, ESR samples were deposited on molybdenum foil. The sample peeled off in flakes after bending the Mo foil and could be sealed immediately without further treatment. The influence of different environments during storage or annealing was studied by removing the samples from the He-filled tubes and sealing them in $\mathrm{Ar}$ or $\mathrm{O}_{2}$ atmospheres or treating them with $\mathrm{HCl}$ or water. The $I_{c}^{R S}$ values were also determined for the material grown on $\mathrm{Al}$ and Mo. Other measurements, like conductivity and infrared spectra, could only be performed on material codeposited on glass or c-Si wafer. We assume for the ESR powder that a high $I_{c}^{R S}$ value is equivalent with porous material and a low value with compact material. However, in view of the strong substrate dependence of the growth and structure development, there might be differences in the structural properties of the $\mu \mathrm{c}$ $\mathrm{Si}: \mathrm{H}$ powder and the codeposited films on glass and c-Si. Future studies will have to clarify this point.

ESR was measured in the X-band at room temperature or at $40 \mathrm{~K}$. Details of the experiment are published elsewhere [22, 23].
Conductivity was measured with coplanar contacts in vacuum soon after deposition. The current-voltage characteristic was measured to assure ohmic contact behaviour. Samples were measured at $200-450 \mathrm{~K}$ with heating/cooling rates of $2 \mathrm{~K} / \mathrm{min}$ in vacuum. Samples were stored alternatively in vacuum or at atmospheric pressure for certain periods of time and then remeasured.

\section{Results}

In Fig. 1, taken from [5], important features of the structure of $\mu \mathrm{c}-\mathrm{Si}: \mathrm{H}$ are shown. From left to right the Figure shows a cross-section through material grown on glass ranging from a high crystalline volume fraction (left) to almost complete amorphous structure (right). The various structural compositions are obtained by an appropriate choice of deposition parameters, such as silane concentration, discharge power, temperature, etc. The individual features have been discussed in great detail in the literature [7, 8, 10$12,21,24-28]$. We use the schematic in an attempt to classify some of the instability effects observed in the material. We distinguish between type I and type II material, which in many, but not all, aspects is equivalent to porous (type I) and compact (type II) material. We have to point out that this classification is not intended to be equivalent with the 'poly I' and 'poly II' type material reported in [27]. The classification is used here only for an easier description of the experimental results. In type I material, which usually has high crystalline volume fractions and large grain sizes, we observe crystalline columns separated by deep cracks, visible in TEM cross-section images [10, 11, 21, 24], strong $\mathrm{Si}-\mathrm{O}$ absorption modes at around $1100 \mathrm{~cm}^{-1}$ in infrared spectra, a predominant $\mathrm{Si}-\mathrm{H}$ stretching mode at $2100 \mathrm{~cm}^{-1}$ indicative of $\mathrm{H}$ bonded onto surfaces [29] and high spin densities $\left(N_{\mathrm{S}}\right)$ at or above $10^{17} \mathrm{~cm}^{-1}$ [15]. Such material yields poor efficiencies if used in solar cells [5-8]. Type II material, which is prepared under conditions closer to all-amorphous growth and which has smaller grain sizes and sometimes distinguishable amorphous volume fractions [10, 11, 21, 24], also shows a columnar structure with deep cracks in cross-section TEM, but shows no (or very little) $\mathrm{Si}-\mathrm{O}$ absorption bands, has predominant $2000 \mathrm{~cm}^{-1} \mathrm{Si}-\mathrm{H}$ stretching modes indicative of hydrogen in a compact environment [29], spin densities of as low as $10^{16} \mathrm{~cm}^{-1}[15]$ and yields higher solar cell efficiencies [5-8]. It is clear that such simple categories will not be

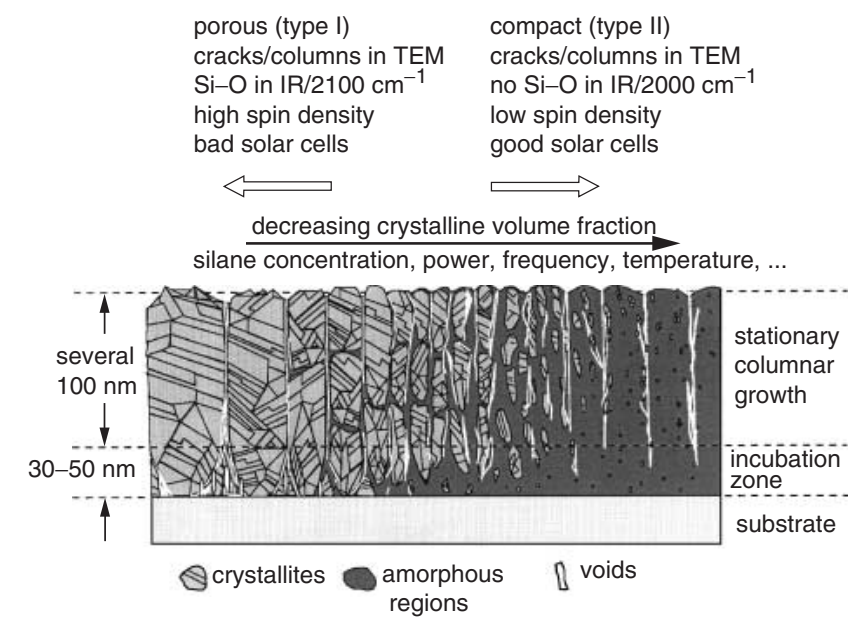

Fig. 1 Schematic diagram showing the prominent microstructure features of $\mu \mathrm{c}-\mathrm{Si}: \mathrm{H}$

From left to right the film composition changes from highly crystalline to predominantly amorphous [5] 
sufficient to classify all instability effects. Some phenomena occur in both types, others may need a further detailed distinction, which may not even be based on material structure features. We stress that such a classification is used here mainly to simplify the description of the experimental findings of the various reversible and irreversible effects.

\subsection{Infrared spectra}

The effect of the pronounced porosity is easily observed in IR spectra. In Fig. 2 IR spectra of two $\mu \mathrm{c}-\mathrm{Si}: \mathrm{H}$ samples prepared by HWCVD are shown. As a semi-quantitative measure of the crystalline volume fraction, the Raman intensity ratio $I_{c}^{R S}[21]$ is indicated in the Figure. The type I sample shows very high $\mathrm{Si}-\mathrm{O}$ modes around $1100 \mathrm{~cm}^{-1}$ and a high $2100 \mathrm{~cm}^{-1}$ absorption mode indicative of $\mathrm{Si}-\mathrm{H}$ surface states. An additional absorption band at 2240$2250 \mathrm{~cm}^{-1}$ is found, which is related to $\mathrm{O}_{2 \ldots 3}-\mathrm{Si}-\mathrm{H}$ [30]. The $\mathrm{Si}-\mathrm{O}$ mode shows clear time dependence and is not observed when the sample is measured directly after deposition or after storage in inert gas or $\mathrm{N}_{2}$ [18]. The type II sample with compact material shows little or no $\mathrm{Si}-\mathrm{O}$ mode and is stable over time. Also, the $2000 \mathrm{~cm}^{-1}$ mode dominates the $2100 \mathrm{~cm}^{-1}$ mode. Note that the type II (compact) sample has a higher $I_{c}^{R S}$, which underlines the problematic distinction of the material into type I and II.

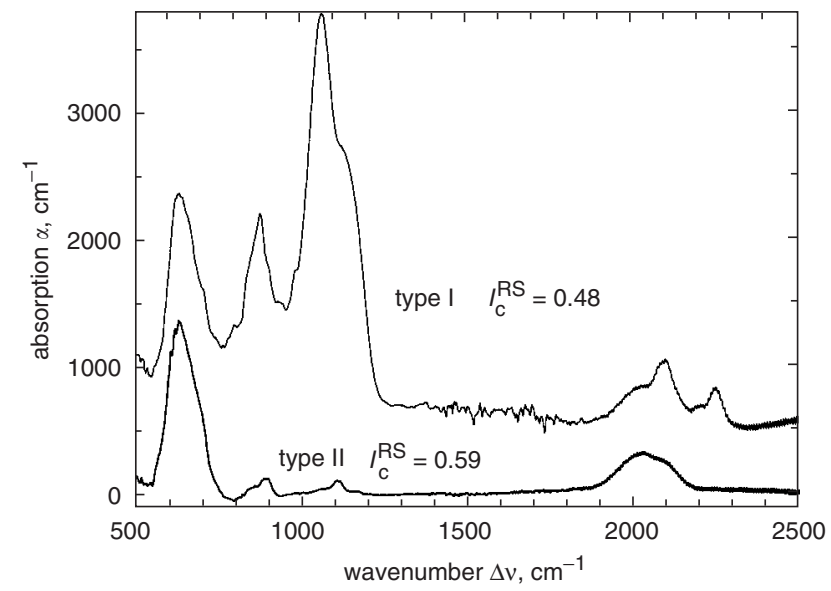

Fig. 2 Infrared absorption spectra of two $\mu c-S i: H$ films prepared by $H W C V D$

The two samples are labelled type I and II, respectively, according to the description given in Fig. 1. The spectra are shifted with respect to each other for clarity

\subsection{Conductivity}

These two samples show a distinctly different influence of storage in air and annealing on the electronic dark conductivity $\sigma_{\mathrm{D}}$. In Fig. $3 \sigma_{\mathrm{D}}$ is shown against $1000 / T$ for the two samples from Fig. 2. After storage in air, for sample type I (Fig. 3a) the conductivity decreases by up to three orders of magnitude. When annealed in vacuum up to $180^{\circ} \mathrm{C}$, the initial $\sigma_{\mathrm{D}}$ is restored. $\sigma_{\mathrm{D}}$ remains at this value when the sample is kept in vacuum. The conductivity decreases again when the sample is put back into air. This cycle can be repeated many times without any sign of fatigue (compare [13]).

Type II samples show a different behaviour. When exposed to air, the conductivity increases (Fig. 3b). Again this change in $\sigma_{\mathrm{D}}$ can be restored when the sample is annealed under vacuum to $180^{\circ} \mathrm{C}$. The conductivity remains at this level when kept under vacuum and increases when exposed to air. Also for type II material the cycles can be repeated many times.

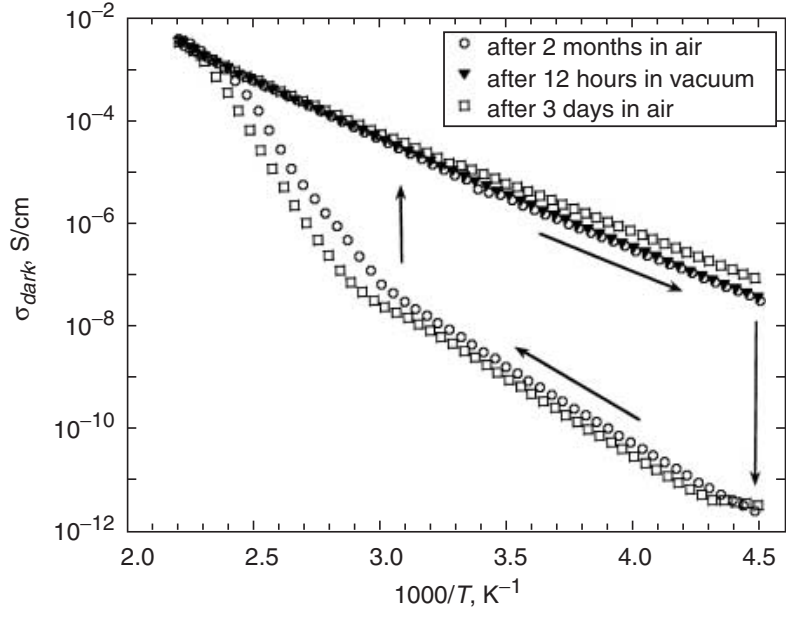

a

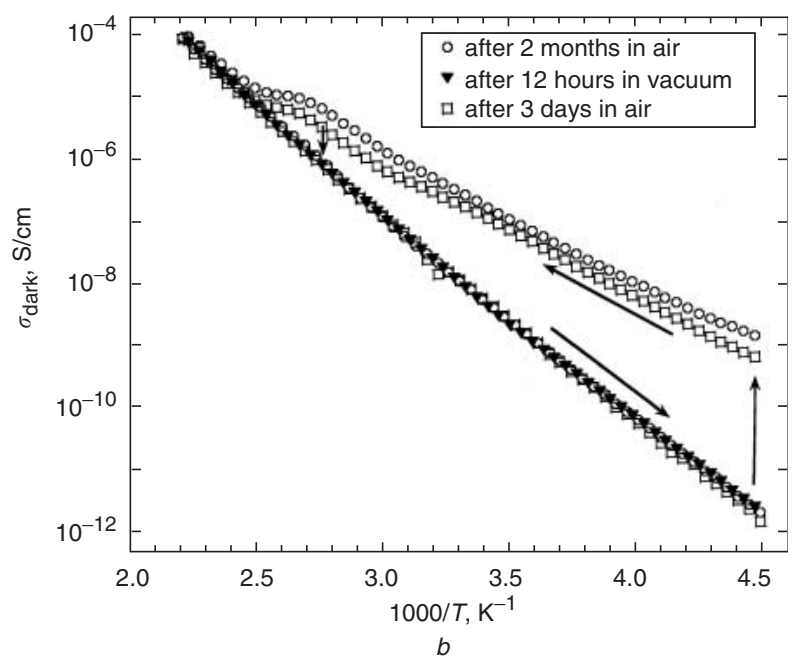

Fig. 3 Dark conductivity of samples prepared with HWCVD from Fig. 2 during various annealing and storage cycles $a$ Type I, $I_{c}^{R S}=0.48$

$b$ Type II, $I_{c}^{R S}=0.59$

\subsection{Electron spin resonance}

The standard procedure for preparing large volume samples for ESR is deposition on Al foil which is etched away in diluted $\mathrm{HCl}$. The remaining powder is filtered and dried at ambient temperature. The material is in contact with water and air for several hours. If the material is prepared on Mo foil, it can be peeled off after deposition and sealed directly in inert gas atmosphere with minimum contact with air and no contact with water or $\mathrm{HCl}$. We observe a considerable influence of the etching/drying process on the spin density in the material. $N_{\mathrm{S}}$ increases and the $g$-value shifts to higher values (Figs. $4 a-4 c$ ). The increase is much stronger in type I material, which is prepared with low SC and which has high crystallinity and pronounced porosity. To see whether the water or the $\mathrm{HCl}$ causes the increase in $N_{\mathrm{S}}$, we rinsed powder which had been prepared on $\mathrm{Mo}$ foil in $\mathrm{H}_{2} \mathrm{O}$ or $\mathrm{HCl}+\mathrm{H}_{2} \mathrm{O}$. Both treatments yielded a similar increase of $N_{\mathrm{S}}$ to a level close to that of material prepared on $\mathrm{Al}$ foil. Etching off the $\mathrm{Al}$ in $\mathrm{HCl}$ does not cause any additional increase of $N_{\mathrm{S}}$ beyond the increase caused by rinsing the powder in water and drying at ambient temperature. This increase upon contact with air or water is reversible when the samples are annealed in Ar as is shown in Figs. 5-7. The high $N_{\mathrm{S}}$ in highly crystalline type I material after air break can be annealed at $80^{\circ} \mathrm{C}$ in Ar to its initial value (Fig. 5). Type II material shows no or very little change upon air break and annealing in Ar in highly crystalline but compact 

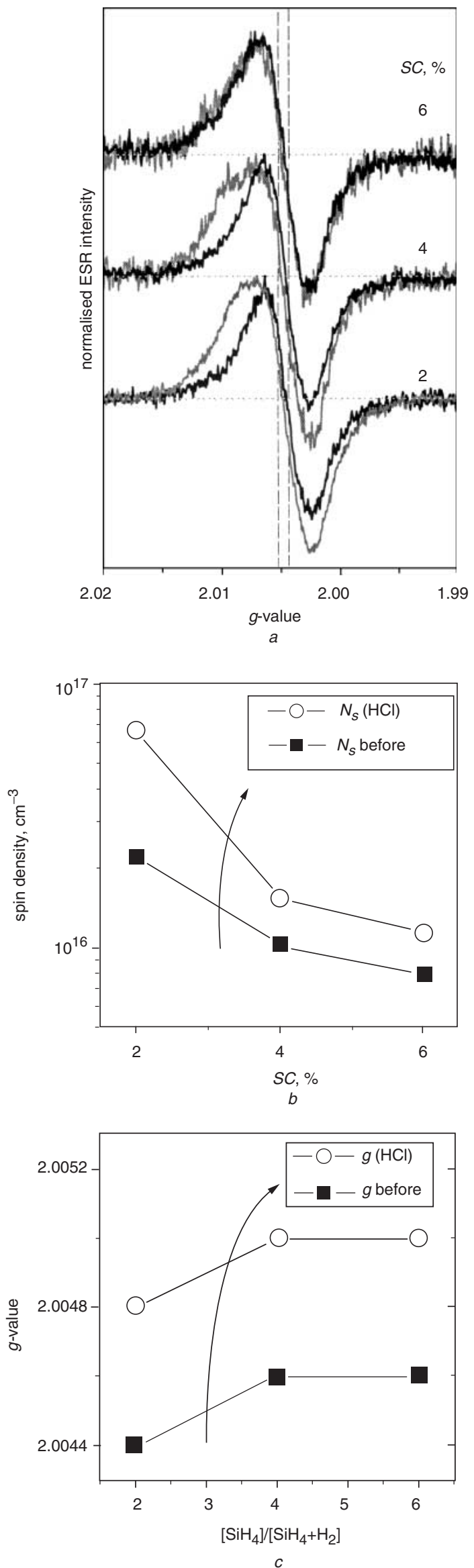

Fig. 4 Room temperature ESR of $\mu c-S i$ :H powder prepared with $P E C V D$ on $M o$ foil and treated in $\mathrm{HCl}$

$a$ Normalised ESR signals, dark trace $=$ as grown, grey trace $=$ after $\mathrm{HCl}$ treatment

$b$ Spin density before and after $\mathrm{HCl}$ treatment

c $g$-value of zero-crossing of resonance line before and after $\mathrm{HCl}$ treatment

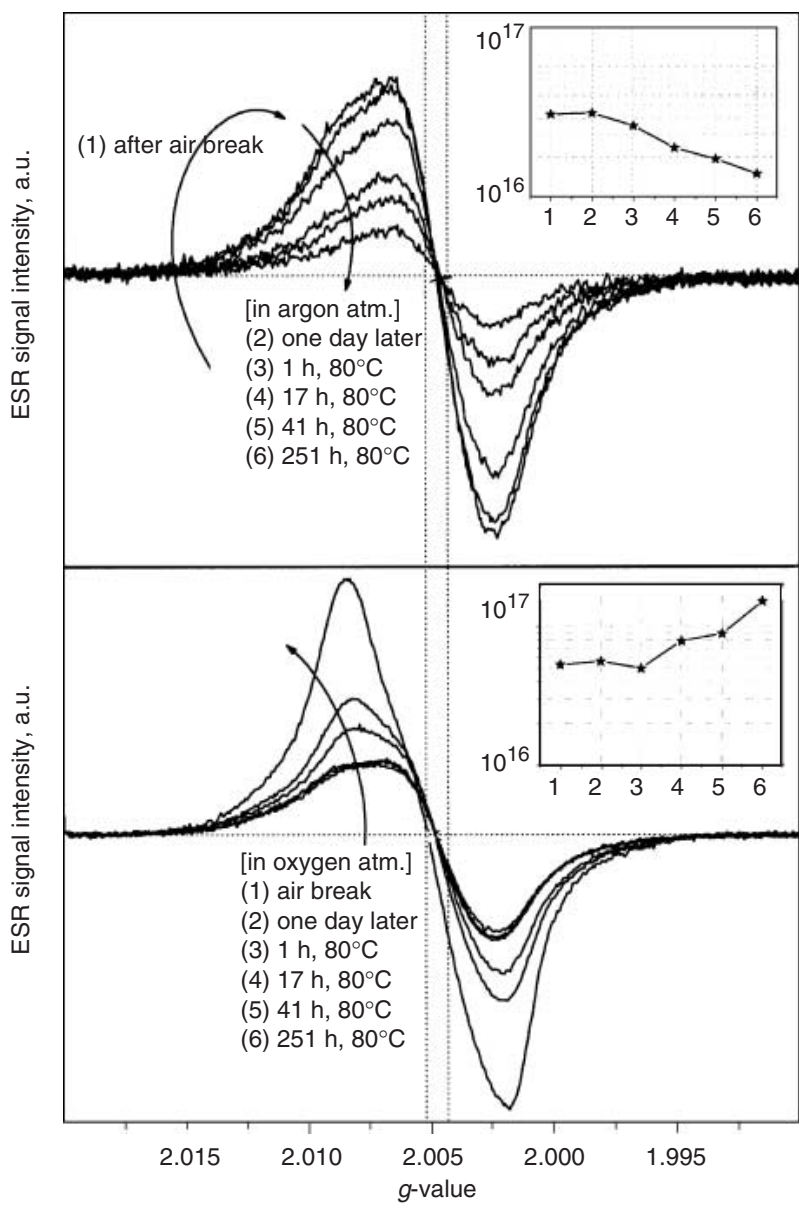

Fig. 5 Room temperature ESR signals of $\mu c$-Si:H powder (type I, highly crystalline and porous) prepared by PECVD

The samples were divided into two parts of approximately equal mass and annealed in $\mathrm{Ar}$ or $\mathrm{O}_{2}$ atmospheres, respectively, after exposure to air

material, which we will call type 'II $a$ ' (Fig. 6). In compact material grown close to the transition between amorphous and crystalline growth conditions (type ' $\mathrm{I} l \mathrm{~b}$ ') we observe some decrease in $N_{\mathrm{S}}$ with annealing in $\operatorname{Ar}$ (Fig. 7). The air break and annealing cycle can be repeated.

When, however, the material is annealed in oxygen atmosphere at $80^{\circ} \mathrm{C}$, there is a nonreversible change of the spin density for type I and type II $a$ material (Figs. 5 and 6). Type II $b$ material shows no effect upon annealing in oxygen (Fig. 7). The spin density change takes place at higher $g$ value and a different spectral shape can be observed. The increase in $N_{\mathrm{S}}$ upon annealing in $\mathrm{O}_{2}$ or air in porous type I material can be restored by an HF dip. This is shown in Fig. 8. In this case, for ease of sample handling, a sample on glass was used. With the reduced sample volume the signalto-noise ratio is considerably lower. However, the increase in $N_{\mathrm{S}}$ after annealing in air and the recovery after etching in $\mathrm{HF}$ can still be easily observed. Because of the low signal intensity, the signal is superimposed by signal traces from the borosilicate glass substrate at around $g=2.001$.

In Fig. 9, the results of exposure and annealing experiments on an n-type sample with around $10^{17} \mathrm{~cm}^{-3}$ phosphorus atoms are shown. The doping shifts the Fermi level towards the conduction band and the well known conduction electron (CE) resonance at $g=1.996-1.998$ can be observed (lower trace in Fig. 9). When the sample is filled into an $\mathrm{O}_{2}$ atmosphere, stored at room temperature or annealed at $80^{\circ} \mathrm{C}$, the $\mathrm{CE}$ resonance decreases and the 


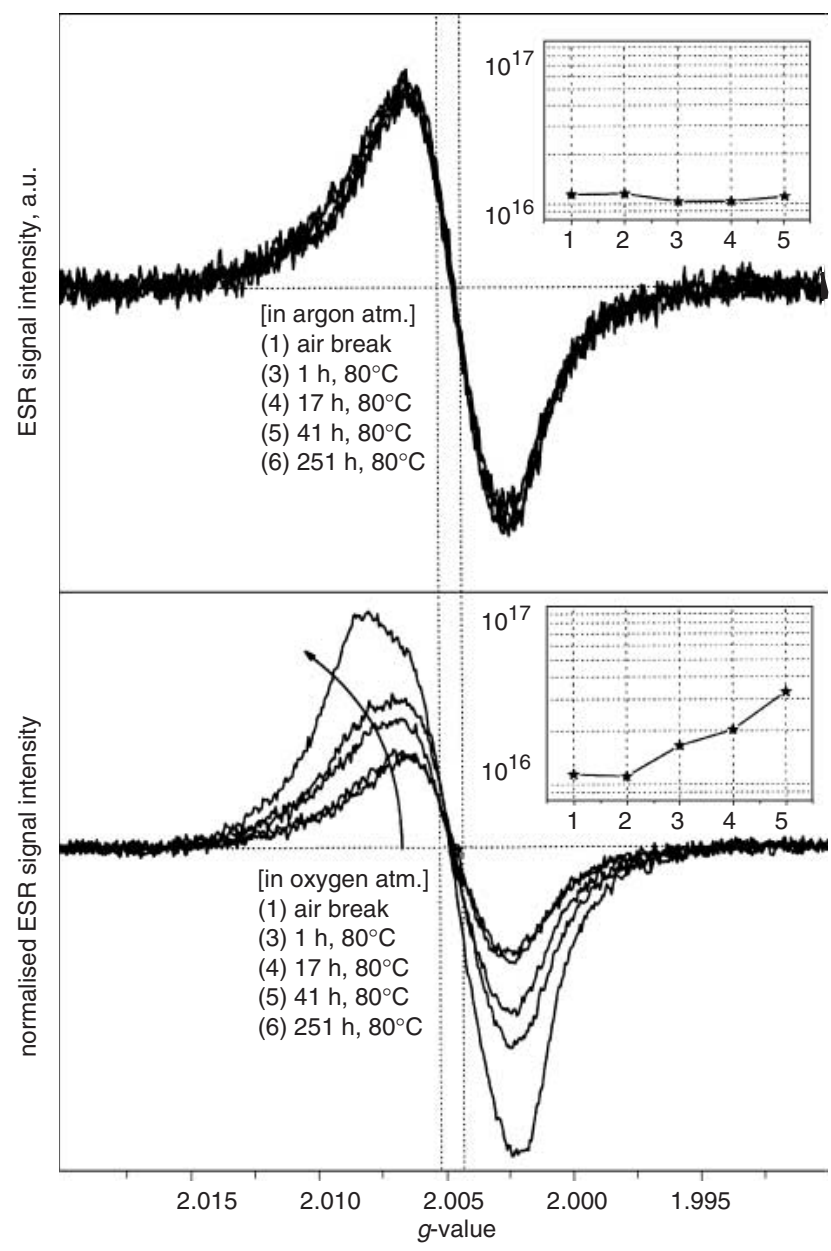

Fig. 6 Room temperature ESR signals of $\mu c-S i: H$ powder (type IIa, highly crystalline and compact) prepared by PECVD

The samples were divided into two parts of approximately equal mass and annealed in $\mathrm{Ar}$ or $\mathrm{O}_{2}$ atmospheres, respectively, after exposure to air

dangling bond (DB) resonance at $g=2.0042-2.0052$ increases.

The influence of annealing at higher temperatures in $\mathrm{Ar}$ or $\mathrm{O}_{2}$ is demonstrated in Fig. 10. The type I sample from Fig. 5 was exposed to air at room temperature for a prolonged period (lower trace in Figs. $10 a$ and $10 b$ ). Upon annealing in $\mathrm{Ar}$ at $160^{\circ} \mathrm{C}$, a strong $\mathrm{CE}$ contribution is observed while the DB signal decreases (upper trace in Fig. 10a). When exposed to air the sample resumes its original state (lower trace). Annealing in $\mathrm{O}_{2}$ at $160^{\circ} \mathrm{C}$, however, results in an irreversible increase of the spin density at $g$-values greater than 2.0052 (upper trace in Fig. 10b).

\subsection{Light-induced degradation in solar cells}

As mentioned above, $\mu \mathrm{c}-\mathrm{Si}: \mathrm{H}$ solar cells show a characteristic change of $V_{\mathrm{OC}}$ as a function of the crystalline to amorphous structure ratio. Three solar cells prepared by HWCVD with different $V_{\mathrm{OC}}$ and different $I_{C}^{R S}$ were exposed to prolonged light illumination $\left(\mathrm{AM} 1.5\right.$ at $\left.50^{\circ} \mathrm{C}\right)$. The solar cell parameters before and after degradation are summarised in Table 1. These solar cells show a clear dependence of light-induced degradation as a function of the amorphous volume fraction. This is shown in Fig. 11 where the normalised solar cell parameters of three cells are plotted against light soaking time. While the sample with high crystalline volume fraction shows no degradation within the experimental error, the samples with a significant

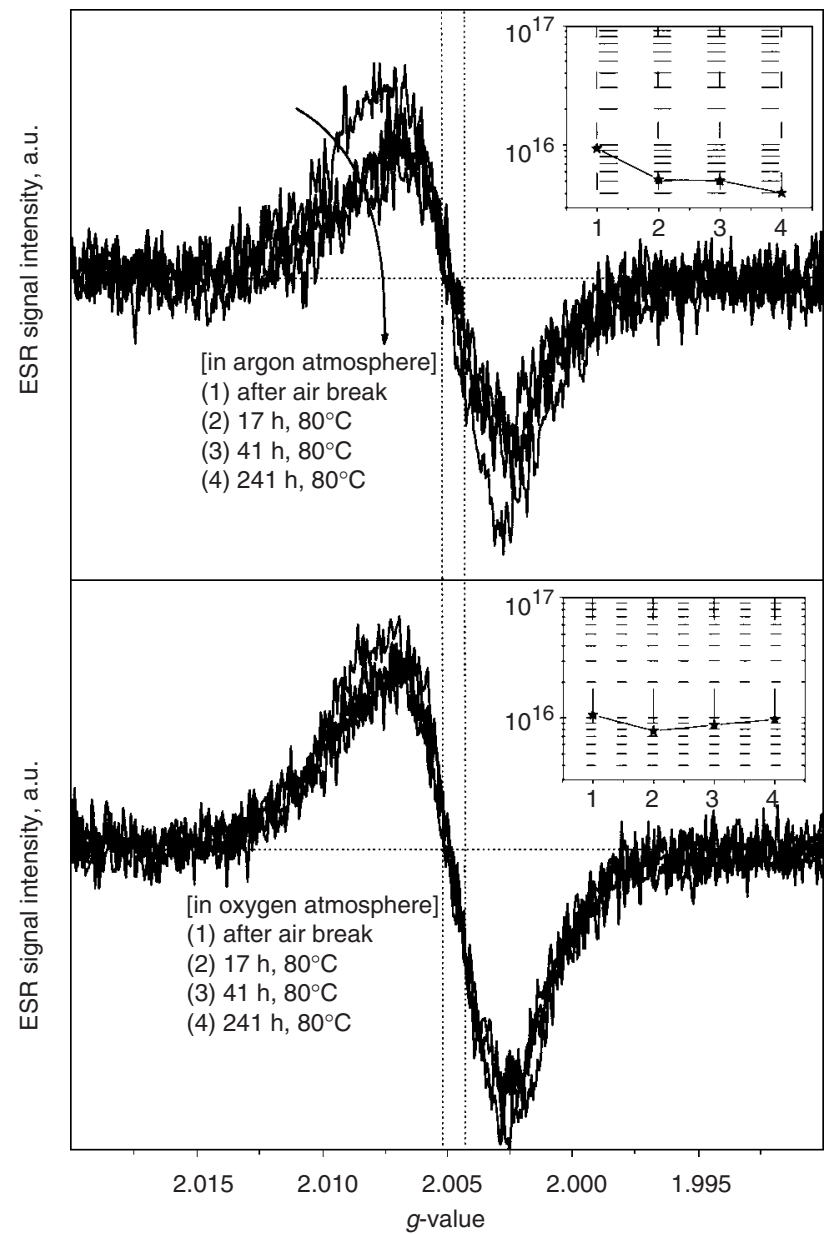

Fig. 7 Room temperature ESR signals of $\mu c-S i: H$ powder (type $I I b$, from transition between amorphous and crystalline growth conditions) prepared by PECD

The samples were divided into two parts of approximately equal mass and annealed in $\mathrm{Ar}$ or $\mathrm{O}_{2}$ atmospheres, respectively, after exposure to air

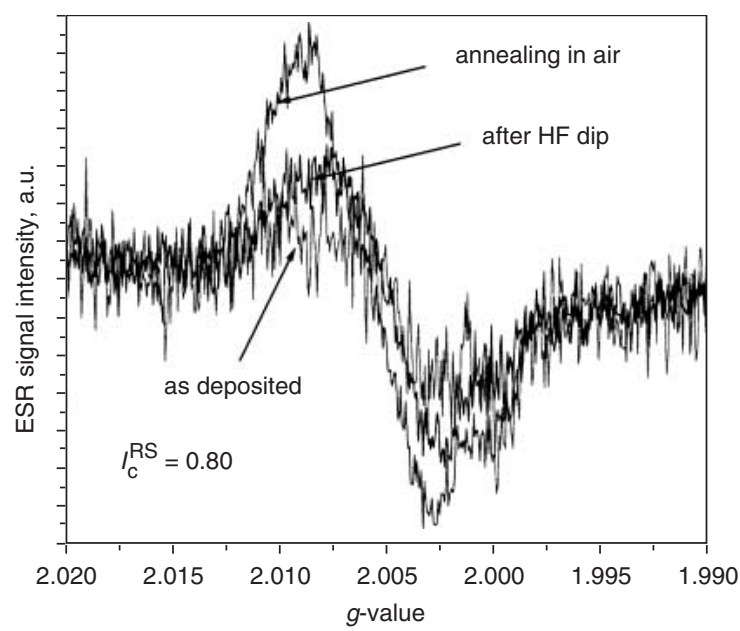

Fig. 8 Room temperature ESR signal of a porous $\mu c-$ Si:H type I sample deposited by PECVD on glass substrate after deposition, annealed in air and after HF etching

amorphous volume fraction show a total efficiency decay of $7-10 \%$. Note that characteristic behaviour is observed like the small increase of the short-circuit current in the cell with the lowest crystalline volume fraction and other behaviour not known from a-Si:H degradation [12]. 


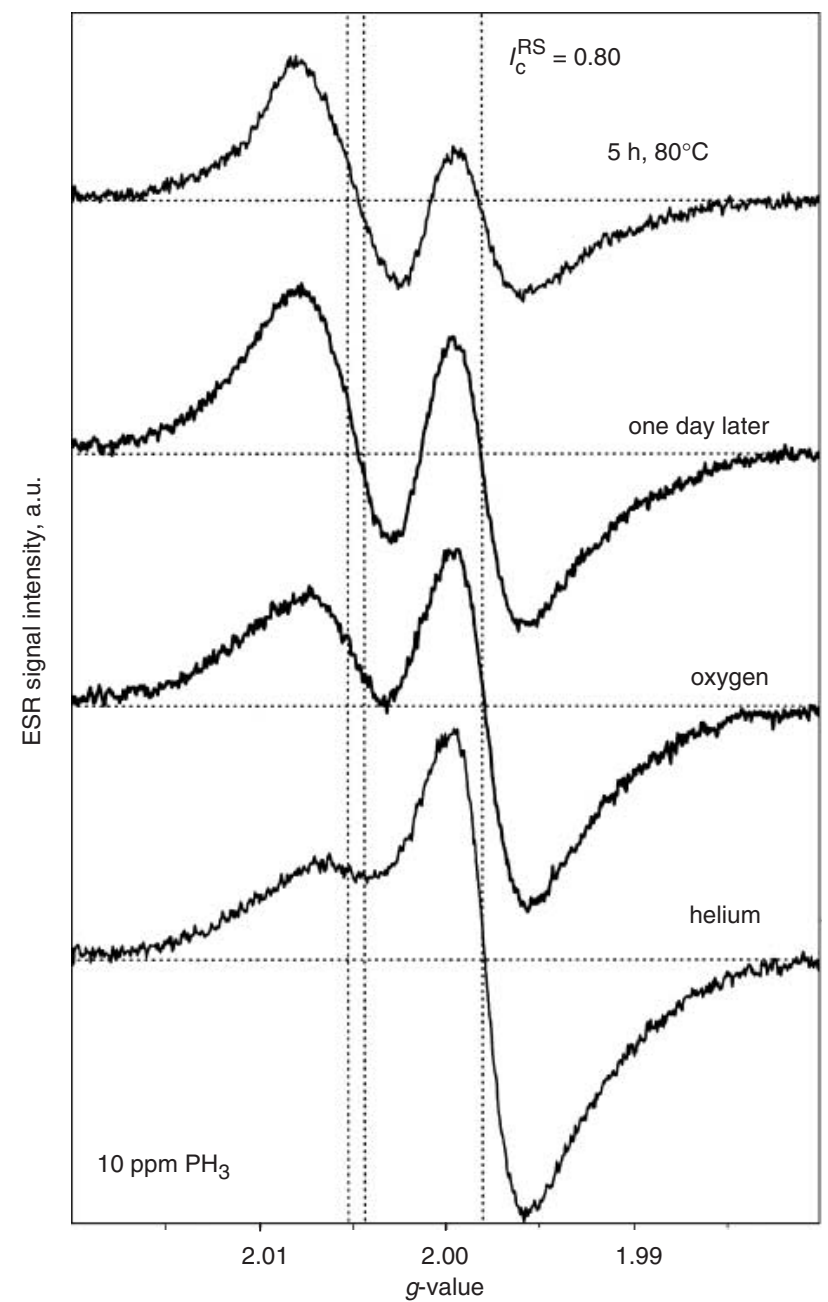

Fig. 9 ESR signals of a $\mu c-S i: H$ type I sample deposited by PECVD with $10 \mathrm{ppm} \mathrm{PH}_{3}$ doping after storage or treatment as indicated in the Figure

Measurements were taken at $40 \mathrm{~K}$

\section{Discussion}

There are a large number of instability and metastability phenomena in $\mu \mathrm{c}-\mathrm{Si}: \mathrm{H}$ which is a matter of great concern for an understanding of the material properties and for possible technological applications of these materials.

Apparently, the porous structure of type I material leads to in-diffusion of atmospheric gases, which results in changes in the electronic conductivity and the spin density. The results show similarities with the findings reported earlier [13, 17, 20]. Differences in the observations could be due to the different material preparation and different experimental conditions and should not be over interpreted at this point. In future studies one will have to take great care to investigate the samples with as much information on the structure as possible, in a well defined state and under
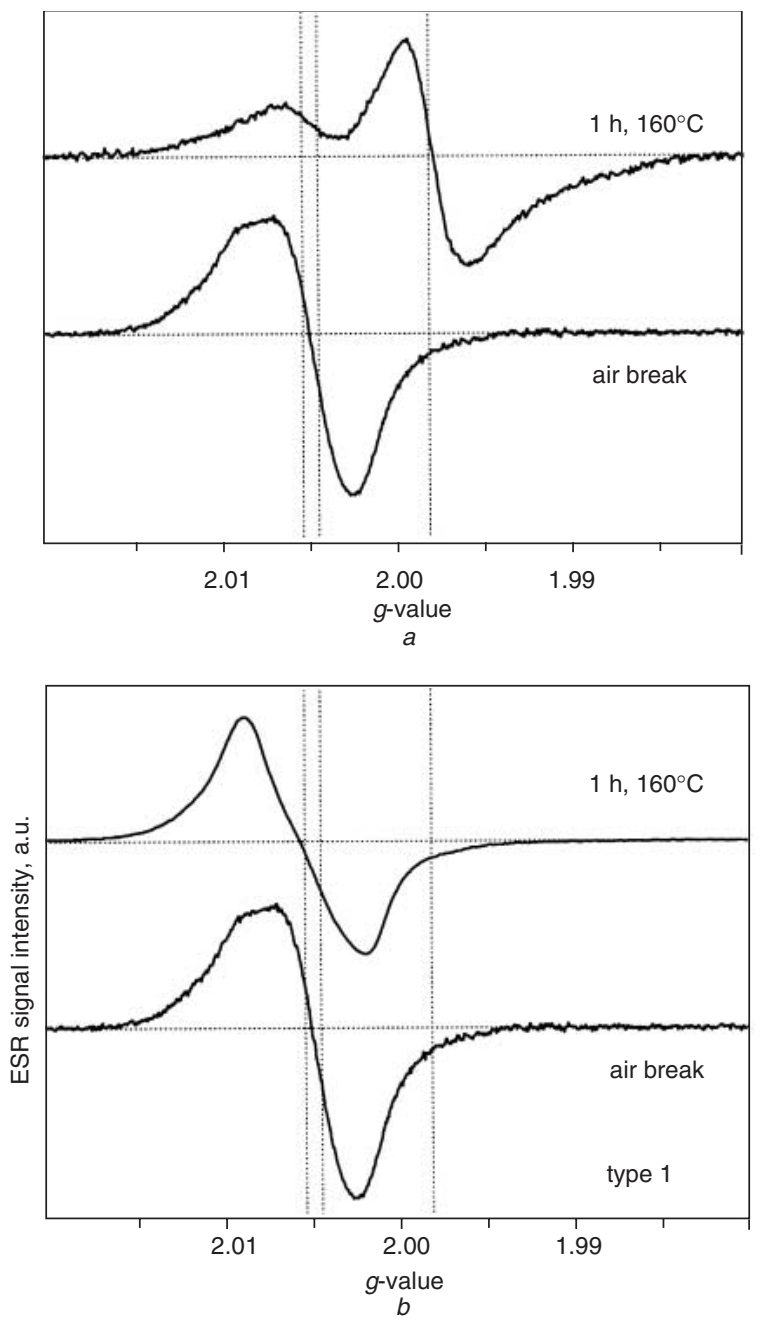

Fig. 10 ESR signals of the PECVD $\mu \mathrm{c}$-Si:H type I sample of Fig. 5 after prolonged exposure to air and after annealing at $160^{\circ} \mathrm{C}$ in $\mathrm{Ar}$ or $\mathrm{O}_{2}$

Measurements were taken at $40 \mathrm{~K}$

$a$ Annealed in $\mathrm{Ar}$

$b$ Annealed in $\mathrm{O}_{2}$

reproducible conditions. For type II material we are not aware of any detailed reports in the literature. The promise of improved stability under illumination is only partly fulfilled. Optimum $\mu \mathrm{c}-\mathrm{Si}: \mathrm{H}$ material for solar cells is found close to growth conditions of amorphous material. This material may include an amorphous phase, which, as in the case of the HWCVD solar cells (Fig. 11), shows degradation.

We will briefly discuss whether the various metastability and instability effects observed in $\mu \mathrm{c}-\mathrm{Si}: \mathrm{H}$ of various structural compositions can be related to each other and whether they have the same origin. We propose that the main effects to consider are adsorption and oxidation on surfaces and light-induced degradation in material containing the amorphous phase. There have been reports and

Table 1: Absolute values of the $I-V$ parameters of the solar cell of Fig. 11 before $\left(t_{s}=0\right)$ and after $\left(t_{s}=1000 \mathrm{~h}\right)$ degradation. The values are averaged over approximately ten cells $\left(1 \times 1 \mathrm{~cm}^{2}\right)$ on a single substrate

\begin{tabular}{lllllllll}
\hline$I_{C}^{R S}$ & \multicolumn{2}{l}{ Efficiency (\%) } & \multicolumn{2}{l}{$V_{\mathrm{OC}}(\mathrm{mV})$} & \multicolumn{2}{l}{$\mathrm{FF}(\%)$} & \multicolumn{2}{l}{$I_{\mathrm{sC}}(\mathrm{mA})$} \\
& $t_{\mathrm{s}}=0$ & $t_{\mathrm{s}}=1000 \mathrm{~h}$ & $t_{\mathrm{s}}=0$ & $t_{\mathrm{s}}=1000 \mathrm{~h}$ & $t_{\mathrm{s}}=0$ & $t_{\mathrm{s}}=1000 \mathrm{~h}$ & $t_{\mathrm{s}}=0$ & $t_{\mathrm{s}}=1000 \mathrm{~h}$ \\
\hline 0.29 & 8.49 & 7.94 & 600 & 580 & 71.0 & 68.2 & 20.04 & 20.05 \\
0.38 & 8.38 & 7.56 & 568 & 558 & 66.7 & 65.3 & 22.02 & 20.80 \\
0.63 & 7.18 & 7.17 & 518 & 507 & 65.8 & 66.2 & 21.48 & 21.38 \\
\hline
\end{tabular}




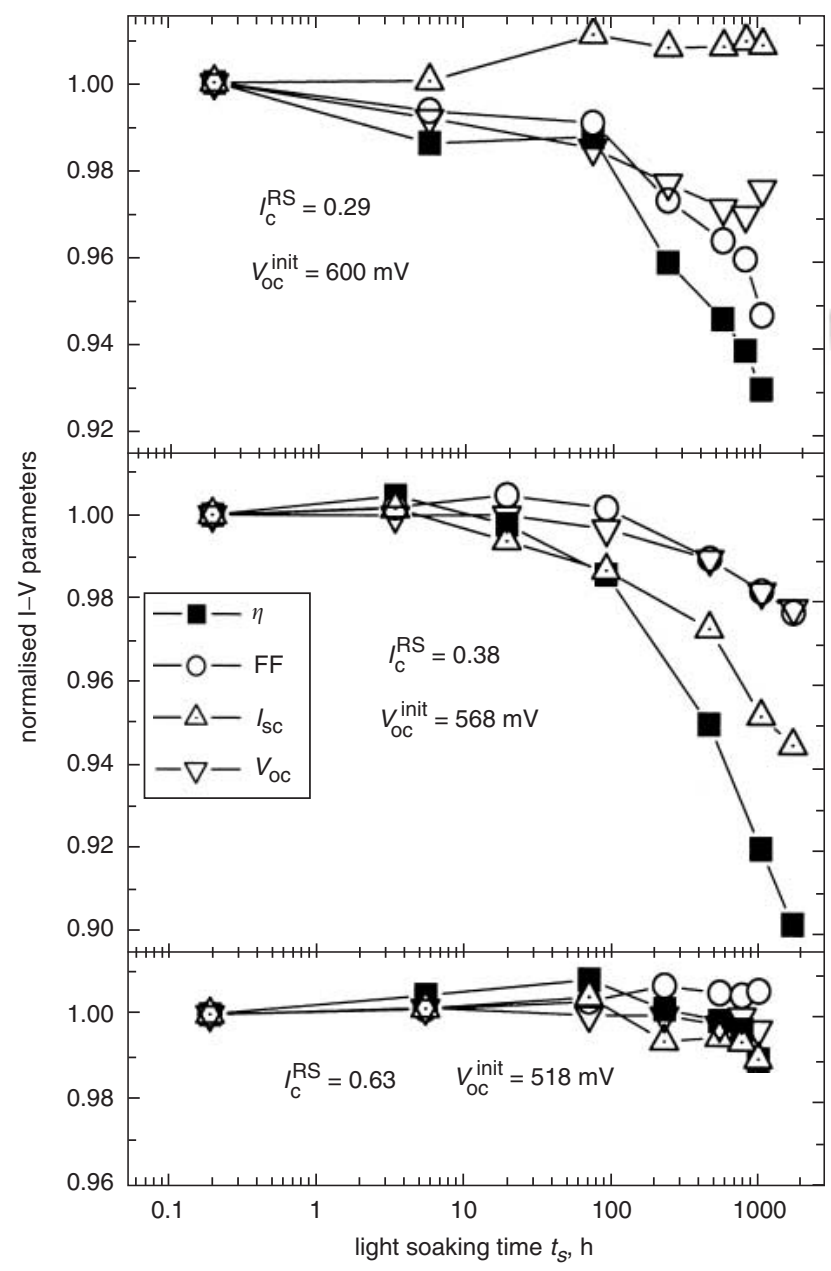

Fig. $11 \mu c$-Si:H solar cell parameters efficiency ( $\eta$ ), fill factor $(F F)$, short-circuit current density $\left(I_{S C}\right)$ and open circuit voltage $\left(V_{O C}\right)$ as a function of degradation time

From top to bottom the material has increasing crystalline volume fractions which typically results in lower $V_{\mathrm{OC}}$ values. The solar cell ilayers were prepared by HWCVD

discussion on further topics related to instabilities and metastabilities in $\mu \mathrm{c}-\mathrm{Si}$ :H. A cooling rate dependent change of the dark conductivity in $\mu \mathrm{c}-\mathrm{Si}: \mathrm{H}$ has been related to metastable hydrogen configurations [19]. As the cooling rate is much lower in the present study, we do not observe any metastability cases where the samples are annealed and cooled in vacuum without exposure to air. The adsorption and oxidation effects dominate. However, similar studies as in [19] should be of interest for material with variation of $I_{c}^{R S}$.

Another source of instability with influence on electronic conductivity, which keeps being reported, are oxygen donors in $\mu \mathrm{c}-\mathrm{Si}: \mathrm{H}[31,32]$. The various types of oxygen donors in crystalline silicon have been and are still being studied in great detail [33]. Generally the properties of oxygen donors in c-Si depend on the thermal history of the material, with process temperatures which are considerable beyond the process temperatures used for $\mu \mathrm{c}-\mathrm{Si}: \mathrm{H}$ preparation. In principle such donors could be passivated by hydrogen, where one could imagine metastable configuration similar to the bond switching models discussed for the explanation of the light-induced metastability in a-Si:H [34]. For $\mu \mathrm{c}$-Si:H however, any clear evidence that oxygen donors exist and are relevant is missing. We shall therefore not discuss these possibilities here.

Let us first compare the magnitude of the states involved which leads to the observation made in the IR, conductivity and ESR experiments. To be detectable in such quantities as the $\mathrm{Si}-\mathrm{O}$ absorption mode in the IR spectra of Fig. 2, the number of $\mathrm{Si}-\mathrm{O}$ bonds has to be of the order of a few 0.1 percent of the total number of bonds, which means a few times $10^{19} \mathrm{~cm}^{-3}$. This has to be compared with the $10^{16}-10^{17} \mathrm{~cm}^{-3}$ spin states which appear as an additional signal contribution in the ESR experiments. With a density of states in the mobility gap of a few times $10^{16} \mathrm{~cm}^{-3} \mathrm{eV}^{-1}$, the creation or recharging of a similar number of states in the gap has a considerable influence on the Fermi level position, which can result in the observed changes in conductivity.

\subsection{Oxidation}

The presence of the $\mathrm{Si}-\mathrm{O}$ absorption mode indicates an oxidation process of $\mu \mathrm{c}-\mathrm{Si}: \mathrm{H}$ material of type I. The magnitude of the $\mathrm{Si}-\mathrm{O}$ mode is linked with the magnitude of the $2100 \mathrm{~cm}^{-1}$ mode, which is indicative of $\mathrm{Si}-\mathrm{H}$ surface states in crystalline material. This oxidation process is thermally activated. It already starts at room temperature, but is considerably faster at $80^{\circ} \mathrm{C}$. The resulting $\mathrm{Si}-\mathrm{O}$ bonds are stable, i.e. the process is nonreversible, at the annealing temperatures of not more than $200^{\circ} \mathrm{C}$ used in the present study. Vepřek et al. report removal of the oxygen only above $1050^{\circ} \mathrm{C}$ [13]. The nonreversible occurrence of additional spins upon annealing in oxygen is linked to this oxidation process. $\mathrm{Si}-\mathrm{O} / \mathrm{Si}$ interface dangling bond defects $\left(\mathrm{P}_{\mathrm{b}}\right.$ centre) are the most likely candidates for this defect. Apparently only a fraction $\left(10^{16}\right.$ of $\left.10^{20}\right)$ of the $\mathrm{Si}-\mathrm{O}$ states observed in the IR give rise to spin-related states. The fact that the increase of $N_{\mathrm{S}}$ after annealing in $\mathrm{O}_{2}$ or air can be restored with an HF dip indicates that this is a surface process. Similar conclusions are presented in [17].

Compact type II material, however, is not, or much less, affected by this oxidation process, at least no effects are visible in the IR. ESR reveals an increase of a possibly $\mathrm{Si}-\mathrm{O}$ related state upon annealing in oxygen of the order of $3 \times 10^{16} \mathrm{~cm}^{-3}$ for type II $a$ material (Fig. 6). Finally, compact material with a significant amorphous phase (type IIb) shows no effect of oxidation in IR or ESR.

The oxidation experiments on n-type ESR powder (type I) show how the CE centres are depopulated by the creation of additional states (Fig. 9). This will occur when the additional states created by annealing in oxygen are located at a lower energy than the CE states. If these states can accommodate additional electrons they will be occupied and pull the Fermi level down. Si-DB at the $\mathrm{Si}-\mathrm{O} / \mathrm{Si}$ interface are a possible origin.

Studies on the influence of irreversible oxidation on conductivity in our material are still underway. It remains to be investigated whether the magnitude of the reversible changes is influenced by the amount of irreversible oxidation of the material [13]. However, material measured after storage in air for more than one year did not show an irreversible change of conductivity, but just the metastable changes discussed below.

\subsection{Adsorption}

Compared with the nonreversible oxidation effects, the effects of adsorption on conductivity and ESR signals can be reversed by moderate temperature annealing in inert gas or long-term storage in inert gas or vacuum. These effects can still be observed after many cycles with no sign of fatigue or accumulation of any irreversible effects. These effects can be related to the adsorption of water or $\mathrm{O}_{2}^{\delta-}[13]$. Unlike the irreversible oxidation of type I material, reversible adsorption cannot be detected in the IR spectra. 
The intensity is too low or the states involved are vibrationally infrared inactive [13].

The reversible change in $N_{\mathrm{S}}$ is only observed in type I material, although all these ESR experiments, apart from the HF dip, were performed on powder material with a presumably large surface area. This increased surface area, however, cannot compensate for the strong porosity of type I structure or reactivity of type I material surfaces leading to a comparable 'surface' in type II material.

It is only possible to speculate about the origin of the reversible changes in the ESR signal. The thermal energies during storage and annealing of the samples are too low for the breaking up and annealing of, for example, Si-DB. If adsorption leads to strong band bending, this could result in bond breaking via the weak-bond (WB) dangling-bond conversion similar to the field effect and doping-induced defect creation in a-Si:H [34]. However, it is difficult to fit the WB-DB conversion to the up and down changes of $\sigma_{\mathrm{D}}$ and $N_{\mathrm{S}}$. Band bending can also result in a change of occupation of states, which leads to the transition from diamagnetic to paramagnetic. Any explanation should consider the corresponding changes in conductivity as shifts of the Fermi level will change the occupation of states and will, in general, change the ESR signal. For these conductivity changes one can assume adsorption of oxygen or water [13]. The two samples for which conductivity was measured here were both undoped. Such material generally shows n-type conduction as determined by the Hall effect. The adsorption of an electron acceptor molecule will create a depletion layer at the surface resulting in a lower overall conductivity. This is equivalent to a movement of the Fermi level away from the conduction band. States in the upper half of the gap become depopulated. When these states change their occupation from, for instance $\mathrm{D}^{-}$(two electrons, no ESR) to $\mathrm{D}^{0}$ (one electron, ESR), an increase in the ESR signal is observed. The details are difficult to predict as they will depend on the relationships between the effective correlation energy of the defects, the energy position of the defects and their distribution in energy.

Quite surprising, but again compatible with the change in occupation of near-surface states, is the effect of annealing at $160^{\circ} \mathrm{C}$ in $\mathrm{Ar}$ of the type I sample, which leads to the appearance of the CE signal (Fig. 10). This means the Fermi level is shifted into the conduction band tail. The observation is in agreement with the changes in $\sigma_{\mathrm{D}}$ upon annealing and the magnitude of $\sigma_{\mathrm{D}}$ (Fig. $3 a$ ). It indicates considerable n-type background doping of this nominally undoped sample. The reason for this remains unknown. After annealing in $\mathrm{O}_{2}$ at $160^{\circ} \mathrm{C}$ the $\mathrm{CE}$ signal does not appear, but instead a strong increase of a resonance at $g>2.0052$ is observed. The different behaviour upon annealing in $\mathrm{O}_{2}$ and $\mathrm{Ar}$ indicate that the observed changes in the ESR signals are not due to a mere thermal annealing effect, but rather to oxidation or adsorption and desorption at the surface.

Factors supporting the picture of a change in occupation are:

(i) The changes occur at $g=2.0052$, a line contribution which is found together with the superimposed signal at $g=2.0043$ in all our $\mu \mathrm{c}-\mathrm{Si}: \mathrm{H}$ material $[15,22,23]$. We consider that it originates from an intrinsic Si-DB defect in the material.

(ii) Various findings, like the parallel existence of the DB $(g=2.0043 / 52)$ and CE $(g=1.996)$ states and the broad distribution in energy of the $g=2.0052$ upon shifting of the Fermi level by doping [23], suggest that the $g=2.0052$ states are located in the upper half of the mobility gap, possibly only in parts of the material.
An alternative explanation for the increase of the $g=2.0052$ resonance would relate the resonance to states of the adsorbed species [13]. Further studies will be needed to conclusively decide between these explanations.

The changes in $\sigma_{\mathrm{D}}$ in type II material are reminiscent of similar effects known from high-quality undoped a-Si:H which shows a higher $\sigma_{\mathrm{D}}$ if exposed to ambient atmosphere. This corresponds to an accumulation layer induced by adsorption. Different grades of passivation of the surface states between type I and II material could be the reason for the two opposite trends $\sigma_{\mathrm{D}}$. We note that for compact type II $b$ material there is a small increase of $N_{\mathrm{S}}$ upon exposure to air (Fig. 7). It will have to be investigated whether this can be related to the increase in $\sigma_{\mathrm{D}}$.

The rather strong effect on $\sigma_{\mathrm{D}}$ in both directions should be considered carefully in routine measurements. A standard annealing procedure in vacuum seems mandatory for a reliable and reproducible measurement. Similarly, one should consider these effects for the evaluation of the spin density.

\subsection{Light-induced degradation}

The observation of SWE in high performance $\mu \mathrm{c}-\mathrm{Si}: \mathrm{H}$ solar cells is troublesome. The amorphous phase in these cells is homogeneously distributed and has very small 'microscopic' thickness. However, the carrier lifetime in these thin layers is long enough for the bond breaking process, which means photoexcited carriers do not move into neighbouring crystalline regions fast enough or else they move from crystalline regions into the amorphous areas. It will be a challenge to optimise the losses due to SWE against the gain in $V_{\mathrm{OC}}$ in material which contains amorphous phase.

Adsorption and oxidation effects will in general also affect the stability of solar cells. Encapsulation of $\mu \mathrm{c}-\mathrm{Si}: \mathrm{H}$ layers by the various other layers in the device could reduce such influence considerably.

\section{Conclusions}

In $\mu \mathrm{c}-\mathrm{Si}: \mathrm{H}$ prepared by HWCVD or PECVD we observe various reversible and irreversible changes which affect the electronic properties of the material and the corresponding solar cells. The phenomena depend strongly on the structural composition of the material. Adsorption and oxidation effects, which can be observed in IR, $\sigma_{\mathrm{D}}$ and ESR, show many similarities to the earlier investigations made on material grown by the chemical transport technique [13]. There are, however, some additional effects which have not been described before. Investigation of these phenomena should be given serious attention in the future.

\section{Acknowledgments}

The authors are very grateful to W. Beyer for helpful discussions on adsorption and oxidation in thin film silicon materials. They thank A. Lambertz, J. Wolff, S. Michel and F. Birmans for technical assistance. Part of this work was supported by the International Bureau of the BMBF, Germany, under project number 42.4.I3B.2.A and the Scientific and Technical Research Council of Turkey (TÜBITAK) under project number TBAG-U/14.

\section{References}

1 Wang, C., and Lucovsky, G.: 'Intrinsic microcrystalline silicon deposited by remote PECVD: a new thin-film photovoltaic material'. Proc. 21st IEEE Photovoltaic Specialists Conf., Kissikimee, FL, USA, 1990, pp. 1614-1618

2 Faraji, M., Gokhale, S., Choudhari, S.M., Takwale, M.G., and Ghaisas, S.V.: 'High mobility hydrogenated and oxygenated micro- 
crystalline silicon as a photosensitive material in photovoltaic applications', Appl. Phys. Lett., 1992, 60, pp. 3289-3291

3 Meier, J., Flückiger, R., Keppner, H., and Shah, A.: 'Complete microcrystalline p-i-n solar cell-crystalline or amorphous cell behavior?', Appl. Phys. Lett., 1994, 65, pp. 860-862

4 Staebler, D.L., and Wronski, C.R.: 'Reversible conductivity charge in discharge-produced amorphous Si', Appl. Phys. Lett., 1977, 31, pp. 292-294

5 Vetterl, O., Finger, F., Carius, R., Hapke, P., Houben, L., Kluth, O., Lambertz, A., Mück, A., Rech, B., and Wagner, H.: 'Intrinsic microcrystalline silicon: a new material for photovoltaics', Sol. Energy Mater. Sol. Cells, 2000, 62, pp. 97-108

6 Klein, S., Wolff, J., Finger, F., Carius, R., Wagner, H., and Stutzmann, M.: 'Microcrystalline silicon prepared by hot-wire chemical vapour deposition for thin film solar cell applications', Jpn. J. Appl. Phys. 2, Lett., 2002, 41, pp. L10-L12

7 Klein, S., Finger, F., Carius, R., Rech, B., Houben, L., Luysberg, M and Stutzmann, M.: 'High efficiency thin film solar cells with intrinsic microcrystalline silicon prepared by hot wire CVD', Mater. Res. Soc. Symp. Proc., 2002, 715, p. A26.2

8 Vetterl, O., Carius, R., Houben, L., Scholten, C., Luysberg, M Lambertz, A., Finger, F., and Wagner, H.: Mater. Res. Soc. Symp. Proc., 2000, 609, p. A 15.2

9 Brammer, T., and Stiebig, H.: 'Defect density and recombination lifetime in microcrystalline silicon absorbers of highly efficient thinfilm solar cells determined by numerical device simulations', J. Appl. Phys., 2003, 94, p. 1035

10 Luysberg, M., Scholten, C., Houben, L., Carius, R., Finger, F., and Vetterl, O.: 'Structural properties of microcrystalline Si solar cells', Mater. Res. Soc. Symp. Proc., 2001, 664, p. A15.2

11 Houben, L. Scholten, C, Luysberg, M, Vetterl, O., Finger, F, and Carius, R.: 'Growth of microcrystalline nip Si solar cells: role of local epitaxy', J. Non-Cryst. Solids, 2002, 299-302, pp. 1189-1193

12 Klein, S., Finger, F., Carius, R., Dylla, T., Rech, B., Grimm, M. Houben, L., and Stutzmann, M.: 'Intrinsic microcrystalline silicon by hot-wire CVD for thin film solar cells', Thin Solid Films, 2003, 430, p. 202

13 Vepřek, S., Iqpal, Z., Kühne, R.O., Capezzuto, P., Sarott, F.-A., and Gimzewski, J.K.: 'Properties of microcrystalline silicon. IV. Electrical conductivity, electron spin resonance and the effect of gas adsorption', J. Phys. C, Solid State Phys., 1983, 16, pp. 2641-264

14 Vetterl, O., Gross, A., Jana, T., Ray, S., Lambertz, A., Carius, R., and Finger, F.: 'Changes in electric and optical properties of intrinsic microcrystalline silicon upon variation of the structural composition', J. Non-Cryst. Solids., 2002, 299-302, pp. 772-777

15 Finger, F., Klein, S., Dylla, T., Baia Neto, A.L., Vetterl, O., and Carius, R.: 'Defects in microcrystalline silicon prepared with hot wire CVD', Mater. Res. Soc. Symp. Proc., 2002, 715, p. A16.3

16 Brüggemann, R., Hierzenberger, A., Wanka, H.N., and Schubert, M.B.: Mater. Res. Soc. Symp. Proc., 1998, 507, p. 921

17 Kanschat, P., Lips, K., Brüggemann, R., Hierzenberger, A., Sieber, I., and Fuhs, W.: Mater. Res. Soc. Symp. Proc., 1998, 507, p. 793

18 Mück, A., Zastrow, U., Vetterl, O., and Rech, B.: in Benninghoven, A., Bertrand, P., Migeon, H.-N. and Werner, H.W. (Eds.) 'Secondary ion mass spectrometry SIMS XII' (Elsevier Science B.V., Amsterdam, 2000), p. 689

19 Nickel, N., and Rakel, M.: 'Hydrogen-induced metastable changes in the electrical conductivity of microcrystalline silicon', Phys. Rev. B, 2001, 65, pp. 041301/1-4

20 Will, D., Lerner, C., Fuhs, W., and Lips, K.: 'Transport and recombination channels in undoped microcrystalline silicon studied by ESR and EDMR', Mat. Res. Soc. Symp. Proc., 1997, 467, pp. 361366

21 Houben, L., Luysberg, M., Hapke, P., Carius, R., Finger, F., and Wagner, H.: 'Structural properties of microcrystalline silicon in the transition from highly crystalline to amorphous growth', Philos. Mag. $A, 1998,77$, pp. 1447-1460

22 Finger, F., Müller, J., Malten, C., and Wagner, H.: 'Electronic states in hydrogenated microcrystalline silicon', Philos. Mag. B, 1998, 77, pp. 805-830

23 Müller, J., Finger, F., Carius, R., and Wagner, H.: 'Electron spin resonance investigation of electronic states in hydrogenated microcrystalline silicon', Phys. Rev. B, 1999, 60, pp. 11666-11677

24 Luysberg, M., Hapke, P., Carius, R., and Finger, F.: 'Structure and growth of hydrogenated microcrystalline silicon: investigation by transmission electron microscopy and Raman spectroscopy of films grown at different plasma excitation frequencies', Philos. Mag. A, 1997, 75, pp. 31-47

25 Ross, C., Herion, J., and Wagner, H.: 'Nucleation and growth analysis of microcrystalline silicon by scanning probe microscopy: substrate dependence, local structural and electronic properties of as-grown surfaces', J. Non-Cryst. Solids, 2000, 266-269, pp. 69-73

26 Vallat-Sauvain, E., Kroll, U., Meier, J., Shah, A., and Pohl, J.: 'Evolution of the microstructure in microcrystalline silicon prepared by very high frequency glow-discharge using hydrogen dilution', $J$. Appl. Phys., 2000, 87, pp. 3137-3142

27 Rath, J.K.: Sol. Energy Mater. Sol. Cells, 2003, 76, p. 431

28 Collins, R.W., and Yang, B.Y.: 'In situ ellipsometry of thin-film deposition: Implications for amorphous and microcrystalline $\mathrm{Si}$ growth', J. Vac. Sci. Technol. B, 1989, 7, pp. 1155-1164

29 Klein, S., Finger, F., Carius, R., Wagner, H., and Stutzmann, M 'Intrinsic amorphous and microcrystalline silicon by hot-wire-deposition for thin film solar cell applications', Thin Solid Films, 2001, 395, pp. 305-309

30 Kniffler, N., Schröder, B., and Geiger, J.: 'Vibrational spectroscopy of hydrogenated evaporated amorphous silicon films', J. Non-Cryst. Solids, 1983, 58, pp. 153-163

31 Torres, P., Meier, J., Flückiger, R., Kroll, U., Anna Selvan, J.A., Keppner, H., Shah, A. Littlewood, S.D., Kelly, IE , and Giannoules, P.: 'Device grade microcrystalline silicon owing to reduced oxygen contamination', Appl. Phys. Lett., 1996, 69, pp. 1373-1375

32 Kamei, T., Wada, T., and Matsuda, A.: Mater. Res. Soc. Symp. Proc., 2001, 664, p. A10.1.1

33 Shimura F. (Ed): 'Oxygen in silicon' Semiconductors and Semimetals, vol. 42, (Academic Press, San Diego, CA, USA, 1994)

34 Stutzmann, M.: 'The defect density in amorphous silicon', Philos Mag. B, 1989, 60, pp. 531-546 